\title{
Knowledge-sharing restrictions in the life sciences: personal and context-specific factors in academia-industry knowledge transfer
}

\author{
Ani Gerbin and Mateja Drnovsek
}

\begin{abstract}
Purpose - Knowledge sharing in research communities has been considered indispensable to progress in science. The aim of this paper is to analyze the mechanisms restricting knowledge sharing in science. It considers three categories of academia-industry knowledge transfer and a range of individual and contextual variables as possible predictors of knowledge-sharing restrictions.
\end{abstract}

Design/methodology/approach - A unique empirical data sample was collected based on a survey among 212 life science researchers affiliated with universities and other non-profit research institutions. A rich descriptive analysis was followed by binominal regression analysis, including relevant checks for the robustness of the results.

Findings - Researchers in academia who actively collaborate with industry are more likely to omit relevant content from publications in co-authorship with other academic researchers; delay their coauthored publications, exclude relevant content during public presentations; and deny requests for access to their unpublished and published knowledge.

Practical implications - This study informs policymakers that different types of knowledge-sharing restrictions are predicted by different individual and contextual factors, which suggests that policies concerning academia-industry knowledge and technology transfer should be tailored to contextual specificities.

Originality/value - This study contributes new predictors of knowledge-sharing restrictions to the literature on academia-industry interactions, including outcome expectations, trust and sharing climate. This study augments the knowledge management literature by separately considering the roles of various academic knowledge-transfer activities in instigating different types of knowledge-sharing restrictions in scientific research.

Keywords Knowledge sharing, Life sciences, Restrictions, Academia-Industry

Paper type Research paper

\section{Introduction}

Knowledge sharing among scientists in academic communities is a central pillar of scientific progress (Dasgupta and David, 1994) because it increases the overall efficiency of the science system by "making knowledge available to others" (Ipe, 2003, p. 341). Prior studies have acknowledged that, in research settings, individual learning that occurs during knowledge sharing can improve the individual's research performance and thus enhance productivity at the team and organizational level (Zhu, 2017). The European Organization for Nuclear Research (CERN) and the Human Genome Project are prominent examples of knowledge-sharing platforms across several countries and disciplines that have led to major scientific breakthroughs. Knowledge sharing involves providing know-how to help
Ani Gerbin is based at the Faculty of Medicine, Center for Proteomics, University of Rijeka, Rijeka, Croatia. Mateja Drnovsek is based at the School of Economics and Business, Academic Unit for Entrepreneurship, University of Ljubljana, Ljubljana, Slovenia.

JEL classification - O34, D83

Received 22 November 2019 Revised 24 February 2020 25 May 2020

Accepted 28 May 2020

() Ani Gerbin and

Mateja Drnovsek. Published by Emerald Publishing Limited.

This article is published under the Creative Commons Attribution (CC BY 4.0) licence. Anyone may reproduce, distribute, translate and create derivative works of this article (for both commercial and non-commercial purposes), subject to full attribution to the original publication and authors. The full terms of this licence may be seen at http:// creativecommons.org/licences/ by/4.0/legalcode 
others and collaborating with others to solve problems and develop new ideas. As such, knowledge sharing is one of the core activities of knowledge management (Anand et al., 2019; Zhang and Jiang, 2015). In academia in particular, knowledge sharing should significantly reduce the duplication of research efforts, make it possible to reproduce research results and, overall, lead to faster accumulation of scientific discoveries (Shibayama et al., 2012). Such knowledge sharing can occur at different levels: individual-individual; individual-group; and group-group (Anand et al., 2019). Knowledgesharing agents can capitalize on knowledge resources to increase their research capabilities and productivity and sustain their competitiveness (Wang and Noe, 2010).

The traditional normative approach to studying the science system (Merton, 1973) views scientific activity as universal to all participants, with common ownership of generated intellectual property (communalism), lack of secrecy, no interest in the personal gains of individual participants (disinterestedness) and organized skepticism. At the same time, fierce competition over gaining priority in publishing and obtaining grant funding has seriously compromised this type of open and free knowledge sharing (Hackett, 1990). In addition, universities worldwide have been encouraged to take a more entrepreneurial role in society as their "third academic mission" (Etzkowitz and Leydesdorff, 2000). This shift has led to more intensive collaboration between academic scientists and industry, and the commercialization of research results. Finally, patents are key mechanisms for transforming scientific discoveries into practical tools. However, patents also have exclusionary effects that can cause the norms of science and the norms of commerce to collide. This conflict may critically impair progress in science (Baldini, 2008; Dasgupta and David, 1994; Geuna and Nesta, 2006; Thompson et al., 2018).

There has been a growing trend of scholarly research on knowledge sharing in the context of academia-industry interactions. However, the recent literature simultaneously investigating knowledge management and technology transfer has mostly been focused on the industrial sector (Barros et al., 2020). Moreover, only a few studies have investigated the determinants of knowledge sharing and knowledge-sharing restrictions by focusing on the variety of forms academia-industry knowledge transfer may take (Blumenthal et al., 1997; Blumenthal et al., 2006; Campbell et al., 2000; Vogeli et al., 2006; Walsh et al., 2007). As a result, the dynamics of knowledge sharing in academic communities are poorly understood. Better understanding of the role of knowledge sharing in academia is necessary to assess the readiness of universities and research institutions to support a knowledge-based society in which expertise, tools and practices are shared (Tan, 2016). Furthermore, studies examining the determinants of restrictions in knowledge sharing in academia have typically investigated barriers to only one form of knowledge sharing (Nelson, 2016), either in publication or in the direct exchange of research data and materials (Walsh and Huang, 2014; Blumenthal et al., 1997; Thursby et al., 2018). Even with these studies, there is insufficient understanding of the antecedents to the development of knowledge-sharing restrictions in science. There is also uncertainty about long-term motivational and contextual mechanisms that either facilitate or impair knowledge-sharing processes in science.

Overall, exploration of knowledge-sharing mechanisms is an important and growing area of research. This study adds to the research on knowledge-sharing mechanisms (Bock et al., 2005; Wasko and Faraj, 2005), particularly in the life sciences (Haas and Park, 2010; Haeussler, 2011), by shedding light on an array of individual and contextual determinants of knowledge-sharing restrictions in academic communities. The conceptual framework is drawn from social capital theory (Bourdieu, 1986; Coleman, 1990). The idea of social capital is useful for conceptualizing the determinants of individual-level knowledge-sharing behavior within a research community, as prior literature has argued that relationships among knowledge-exchange actors are based on trust, reciprocity and similar characteristics (Zhu, 2017). 
The first contribution of this study is to clarify the nature of the contextual mechanisms through which different types of knowledge-sharing restrictions emerge. A unique empirical sample of 212 life science researchers was used to identify and empirically test the antecedents to the following five types of knowledge-sharing restrictions:

1. restrictions in the content of publications co-authored with other academic researchers ("co-author content");

2. timing restrictions of co-authored publications ("co-author delay");

3. sharing restrictions during public presentations of research results ("presentation");

4. restrictions with the sharing of unpublished knowledge, information and materials ("unpublished exchange"); and

5. restrictions with the sharing of published knowledge ("published exchange").

By investigating restrictions in public presentations of research results and restrictions in the content and timing of co-authored publications, which have so far not been represented in the literature, the study makes a significant contribution to existing knowledge on sharing in academia. Moreover, the study integrates and deepens this body of research by distinguishing between unpublished and published knowledge when examining the impact of academia-industry knowledge transfer on knowledge-sharing restrictions. Drawing from the literature, this study hypothesizes three different categories of academia-industry knowledge transfer as possible predictors of knowledge-sharing restrictions. The focus is on academic communities, considering the immanent need to assess how the increased level of business-oriented activities in the science system has affected knowledge sharing in academia. It is important to understand why researchers sometimes hide their knowledge despite the requirements for sharing and dissemination embedded in the academic process (Hernaus et al., 2019). Therefore, a more thorough understanding of the antecedents that mitigate knowledge-sharing restrictions is crucial.

The second contribution stems from the development of the study's conceptual model of the antecedents to knowledge sharing, which is rooted in social capital theory. This model offers a foundation for understanding the relationship between sharing norms and knowledge-sharing restrictions within communities of practice, which are a common phenomenon in life sciences research. Such communities of practice involve work-related groups of individuals who share common interests and problems and learn from each other (Zhu, 2017). The conceptual foundations of social capital theory (Bourdieu, 1986; Coleman, 1990) offer the basic logic as to why people may be motivated to share knowledge with other members of a community. In this context, sharing outcome expectations, trust, reputation and institutional sharing climate are important antecedents to the emergence of knowledge-sharing restrictions. This conceptual model adds structure to a relatively dispersed literature on knowledge-sharing mechanisms in academia. In doing so, the focus is expanded beyond patenting to explore alternative mechanisms of academia-industry knowledge transfer. This is instrumental considering that patenting is only one of many ways to transfer knowledge from academia to industry, including industry collaboration, intellectual property-related activities and academic entrepreneurship-related activities (Nelson, 2016).

Finally, this study proposes several important policy implications based on the finding that not all academia-industry knowledge-transfer activities are associated with all types of knowledge-sharing restrictions. The findings also indicate that, even in settings where there is a relatively low level of researcher engagement in academia-industry knowledge transfer, such activities can positively correlate with knowledge-sharing restrictions. This suggests that changes to the traditional normative framework of science have not only occurred in academic environments with an established history of technology transfer. Consequently, policymakers and managers should devote more attention to the proper management of 
knowledge generated in academia by thoroughly evaluating both the societal and commercial value of that knowledge before deciding on the mode of further dissemination and exploitation. The study further proposes that, when discussing barriers to knowledge sharing in academia, researchers and practitioners must consider not only the relationship with different types of academia-industry knowledge transfer, but also the role of researchers' personal characteristics and motivations, as well as context-specific determinants of knowledge sharing. Specific policy recommendations include enhancing efforts to promote a knowledge-sharing culture through targeted training for researchers on the importance of sharing, the use of open science support infrastructures and the development of research funding and academic promotion schemes that recognize open knowledge sharing and encourage regular interactions among researchers to facilitate trust-building and reciprocity.

In the next section, this paper reviews the extant literature on the different pathways of interaction between academia and industry, emphasizing the knowledge-sharing restrictions that may occur. Drawing from the described conceptual framework, hypotheses are developed on different types of knowledge restrictions, the motivations of researchers to restrict knowledge and associated contextual factors. The paper then describes the methodological procedure, research instrument used in the study, the data sample and method of analysis. Finally, the findings and implications for theory and practice are discussed.

\section{Literature and hypotheses}

Knowledge sharing has been seen as one of the key activities of knowledge management (Zhang and Jiang, 2015). Prior research in this area has investigated the role of the organizational context, interpersonal and team characteristics, cultural characteristics, individual characteristics and motivational factors in knowledge sharing (Zhu, 2017; Wang and Noe, 2010) between individuals, teams and institutions (Anand et al., 2019), mostly in the context of for-profit organizations. While some authors have focused on the likelihood or extent of knowledge sharing (Chiu et al., 2006; Ku, 2019), knowledge-sharing intentions (Bock et al., 2005; Fullwood et al., 2013) or collaboration (Gulbrandsen and Smeby, 2005), others have concentrated on the action or process of knowledge exchange (Bouty, 2000). Some studies have measured the lack of knowledge sharing or knowledge withholding (Blumenthal et al., 2006). Finally, recent studies in the management area (Connelly et al., 2012; Gagné et al., 2019; Hernaus et al., 2019; Semerci, 2019) have argued that knowledge hiding is a construct that is distinct from knowledge sharing or knowledge hoarding (accumulation), because it is characterized by purposeful concealment or withholding upon request. This study uses the term knowledge-sharing restrictions to account for a variety of situations that may occur in the process of sharing knowledge between academic researchers. Researchers may, for example, intentionally and explicitly refuse to share knowledge directly with other researchers or publicly; ignore or forget other researchers' requests; only partially comply with such requests; or delay a response or publication.

When investigating restrictions to scientific knowledge sharing in the context of academia-industry interactions, patenting has been seen as the dominant knowledgetransfer mechanism. In the life sciences, patenting is mostly considered an investment incentive, given how risky it is to develop new biopharmaceutical products and the level of time and financial resources required (Kneller, 2001). At the same time, the patenting and exclusive licensing of life sciences research discoveries has the potential to increase the costs of basic research and inhibit the free sharing of knowledge and innovation processes (Heller and Eisenberg, 1998). Murray and Stern (2007) analyzed 169 patent-paper pairs, finding modest evidence that patenting has a negative impact on knowledge diffusion, measured using the citation rates of scientific publications before and after the granting of the associated patents. Similar results were obtained by Bruggemann et al. (2016) who 
found that the presence of intellectual property rights decreased the number and sophistication of innovations and contributed to a shift in behavior toward less valuable innovations. A recent study by Lee (2018) identified a nonlinear inverted U-shaped relationship between academic patenting and publishing. Thompson et al. (2018) found evidence that the licensing of academic patents had a negative effect on the citations of related publications in scientific journals, in the case of patented discoveries to be used as research inputs by other researchers.

Conversely, other studies have not supported the negative relationship between scholars' involvement in patenting and their scientific output in terms of number of publications (Agrawal and Henderson, 2002; Bikard et al., 2018; Fabrizio and Di Minin, 2008; Gans, 2017). In fact, available evidence suggests that scientists who have a higher research output are generally more likely to become inventors (Breschi and Catalini, 2010). However, when knowledge sharing is measured as the direct exchange of research materials and information among members of the academic community, empirical studies have uncovered possible restrictions depending on the extent to which researchers are involved in patenting activities. Walsh et al. (2007) showed that US biomedical researchers in genomics and proteomics had more difficulties accessing tangible (materials, reagents) research inputs than they did intangible ones. Caulfield et al. (2008) and Davis et al. (2011) conducted surveys to find that Canadian and Danish life scientists had negative attitudes and skepticism toward the impact of university patenting on the norms of open science and academic research freedom.

In practice, the involvement of academic researchers in commercialization activities can critically impair knowledge sharing in academia, as emphasized by Czarnitzki et al. (2015). Based on a sample of German scientists, Czarnitzki and colleagues argued that scientists with industry funding were more likely to deny requests for research inputs than those without. Salandra (2018) found that selective reporting of research results was more likely with industry-funded clinical studies involving industry-affiliated authors. Campbell et al. (2002) revealed that involvement of university-based research in commercialization (measured by the level of industry research funding, patenting, licensing, spin-offs and/or new product development) was significantly associated with the increased likelihood of data withholding (also confirmed by Blumenthal et al., 1996; Walsh et al., 2007). Furthermore, Blumenthal et al. (1997) argued that both involvement in an academia-industry research relationship and engagement in the commercialization of university research were associated with publication delays, but only the latter was associated with refusal to share research results upon request. Shibayama (2012) observed that commercial activity had facilitated secretive publication and non-compliant behavior in material transfer among Japanese scientists, but found no significant effects for collaboration with industry or funding from industry.

To date, the focus of prior literature has been on certain types of knowledge-sharing restrictions, such as the direct sharing of materials and data among researchers and in publication (Nelson, 2016). For example, Walsh and Huang (2014) investigated how the commercialization of academic science (industry funding and patenting) has affected the publication secrecy of research results (e.g. not publishing, partial publication and publication delay). In another study, Blumenthal et al. (1997) studied the relationship between involvement in academia-industry research and the commercialization of university research, and publication delays and refusal to share research results upon request. Thursby et al. (2018), meanwhile, focused on researchers' motivations to disclose their results prior to publication. Empirical research on other types of knowledge-sharing restrictions, such as those found in co-authored publications with academic collaborators from other research groups, presentations at scientific conferences or via material transfer agreements, has been scant (Haeussler et al., 2014; Rodriguez et al., 2007; Schaeffer, 2019; Shibayama et al., 2012). Although the existing literature supports the premise that the 
relationship between academic-industry knowledge transfer and knowledge-sharing restrictions varies, the predominant focus on patenting as the main knowledge-transfer mechanism has limited the generalizability of the findings. In line with this observation, a comprehensive literature review by Perkmann et al. (2013) points to the lack of understanding about the consequences of involvement in particular types of academia-industry collaboration for research activities in academia and calls for further studies to provide new empirical evidence.

This study expands the focus of this area of research beyond patenting to consider other mechanisms of academia-industry knowledge transfer, including industry collaboration, intellectual property-related activities and academic entrepreneurship-related activities. This broader focus is critical, given that patenting is only one of many ways to transfer knowledge from academia to industry. Below, the relevant streams of literature are examined to develop hypotheses, organized according to the type of academia-industry knowledge transfer.

\subsection{Academia-industry interactions and knowledge-sharing restrictions}

Researchers can connect with industry through collaborative research projects, sponsored research, consultation and presentations for the industry, personnel exchange and joint supervision of PhD students or joint publication (Blumenthal et al., 1996; Gaughan and Corley, 2010). Because commercial interests are at stake, industry often requests that academic researchers delay publication of the research results generated through collaborations until the commercialization potential of the results is clear. Because the content of the manuscript is typically subject to industry evaluation, restrictions during the publication process are to be expected. This study argues that similar motivations will lead academic researchers to restrict knowledge during public presentations at scientific conferences, and when directly sharing research materials and information with other researchers in the academic community. This is hypothesized as follows:

H1a. The more a researcher is involved in collaboration with industry, the more she/he is likely to restrict knowledge sharing in the content and timing of publications coauthored with other academic researchers, public presentations of their research results and exchange of published and unpublished knowledge.

Prior research evidence has suggested that knowledge-sharing restrictions are primarily associated with time restrictions in the dissemination of publication when the knowledgetransfer activities are related to intellectual property, for example, invention disclosure, patenting and licensing either at the individual or institutional level through technology transfer offices (TTOs) (Blumenthal et al., 2006; Walsh and Huang, 2014). In particular, TTOs typically require several months to review research results that are filed, assess their patentability and prepare the patent application. During this time, the results need to be kept confidential. For similar reasons, during this time, academic researchers must refrain from publicly presenting their research results at scientific conferences or other public events. The following hypothesis is proposed:

H1b. The more a researcher is involved in intellectual property protection-related knowledge-transfer activities, the more she/he is likely to experience knowledgesharing restrictions regarding the timing of publication and during public presentation of research results.

Researchers can also actively engage in commercial activities through starting a company and/or managing spin-off companies through market dissemination of their research results. Such activities are likely to take substantially more of their time than being involved in an industry collaboration or patenting activities (Shibayama, 2012). This is why such researchers usually have less time to respond to requests from other academic researchers for their research materials and data, both published and unpublished. Moreover, when 
researchers start earning revenue by commercializing their research results, their research will generally no longer be accessible to other academic researchers on a non-commercial, free-of-charge, collaborative basis. This leads to the following hypothesis:

H1c. The more a researcher is actively involved in academic entrepreneurship, the more she/he is likely to restrict direct sharing of his/her unpublished and published research results with other academic researchers.

\subsection{Researchers' motivations for restricting knowledge sharing}

Social capital theory (Bourdieu, 1986; Coleman, 1990) provides a logic as to why people are motivated to share knowledge with other members of a community. The theory analyzes the value of different aspects of an individual's social network in facilitating the actions of actors within the network. Nahapiet and Ghoshal (1998) distinguished between the structural, relational and cognitive dimensions of social capital, the first referring to social interactions, the second to trust (the norm of reciprocity and identification) and the third to shared understanding (i.e. vision and language) between interacting parties.

This study focuses on trust as a key component of the relational dimension of social capital. According to Blau (1964), trust emerges when past positive interactions lead to expectations about positive future interactions; this, in turn, builds good exchange relationships and positively contributes to levels of sharing (Zhu, 2017; Bouty, 2000). Examining the behavior of business students, Connelly et al. (2012) found a direct relationship between distrust (as a construct distinct from trust) and different types of knowledge hiding (see also Hernaus et al., 2019). Trust is conceptualized in this research as an important determinant of knowledge-sharing restrictions in the direct, informal exchange of unpublished and published knowledge (information, data and materials) with other researchers in academia (Wang and Noe, 2010). When researchers have negative past experience in interactions with knowledge-requesting parties, they will be less willing to share knowledge in the future. Such negative past experiences can refer to the requesting researcher's lack of acknowledgment in a publication to which the academic researcher contributed his or her research results, data or materials. Moreover, lack of trust can simply be caused by a lack of personal acquaintance with the knowledge-requesting parties. By contrast, the more an academic researcher generally perceives the academic community as trustworthy and expects other researchers to act consistently in communication, the fewer restrictions are expected in the sharing of scientific knowledge. The reasoning is similar for sharing when it comes to publishing in co-authorship with other research groups. In this case, the lack of trust is expected to cause content and timing restrictions. When a researcher believes that the academic community will normally not take advantage of him/her despite an emerging opportunity, she/he is expected to engage in sharing restrictions during public presentation of scientific results to a lesser extent. This reasoning leads to the following hypothesis:

H2. The level of a researcher's perceived trust is negatively related to knowledge-sharing restrictions in the exchange of published and unpublished knowledge, the content and timing of publications co-authored with other academic researchers and during public presentations of research results.

Prior literature has suggested that knowledge sharing is likely to be driven by outcome expectations. Following Chiu et al. (2006), this study empirically examines the role of two types of outcome expectations in knowledge-sharing restrictions in an academic community: personal outcome expectations and community-related outcome expectations. In the context of this study, personal outcome expectations refer to the consequences an academic researcher expects for himself/herself as a result of his/her involvement in knowledge sharing. Community-related outcome expectations refer to the consequences a researcher expects for the academic community to which he/she belongs. Both types of 
outcome expectations are likely to be negatively related to all investigated types of knowledge-sharing restrictions. When a scientist feels that by sharing knowledge he/she will be happier, more accomplished and better connected to the academic community he/she belongs to, she/he will be less inclined to impose sharing restrictions. Likewise, when a scientist perceives sharing as beneficial for the accumulation of knowledge and growth of the academic community in which he/she operates, she/he will be less likely to restrict access to his/her knowledge:

H3a. Personal outcome expectations are likely to be negatively related to knowledgesharing restrictions in the content and timing of publications co-authored with other academic researchers, public presentations of research results and exchange of published and unpublished knowledge.

H3b. Community-related outcome expectations are likely to be negatively related to knowledge-sharing restrictions in the content and timing of publications coauthored with other academic researchers, public presentations of research results and exchange of published and unpublished knowledge.

Reputation among peers is another potentially important predictor of academic researchers' knowledge-sharing behavior. In this study, the term "reputation" encompasses the relevance academic researchers attach to different indicators of scientific performance, such as number of publications, journal impact factor, number of received citations and number of awards. Haeussler and Colyvas (2011) found that reputation based on publications is positively related to general sharing, for example, through public presentations. The assumption based on this empirical evidence is that when researchers openly share their research results with the general public, they communicate their progress to the audience, thereby increasing their recognition among peers and awareness of their achievements. Other studies have also shown that sharing is significant in sustaining and increasing the actors' reputation in their communities (Amayah, 2013; Wasko and Faraj, 2005). It is hypothesized that the open sharing of knowledge, both via publications and presentations and through direct exchange of research data and materials, increases the number of opportunities for researchers to forge new collaborations with other research groups, which can consequently lead to better scientific performance and better reputation among peers:

H4. A researcher's reputation will be negatively related to knowledge-sharing restrictions in the content and timing of publications co-authored with other academic researchers, public presentations of research results and exchange of published and unpublished knowledge.

\subsection{Contextual factors and knowledge-sharing restrictions}

Blumenthal et al. (2006) found that increasing competitiveness among academics had led to high pressure related to priority in publishing, and this was positively associated with publishing withholding among genetics researchers. The survey conducted by Caulfield et al. (2008) identified competition as a primary reason for stem cell researchers' refusals to share research materials with peers. Vogeli et al. (2006) showed that scientific trainees in highly competitive research groups were more likely to report having denied requests for information, data and materials from other researchers compared to trainees in lowcompetition groups. Walsh et al. (2007) found that an increase in the number of competitors was associated with greater denial to share research materials. The study by Haeussler et al. (2014) reported that the perception of a degree of competitiveness in a specific scientific field was negatively associated with both general and specific sharing of knowledge.

Based on the evidence, this research proposes that academic researchers who perceive their scientific field as being highly competitive will be more likely to engage in all types of 
investigated knowledge-sharing restrictions. The more competitive a research environment is, the more restrictions are expected with respect to the publishing activity of academic researchers. Researchers will be more likely to intentionally omit research results from manuscripts when submitting them for review or publication to protect their scientific lead in the field. Restricting knowledge sharing is a way of buying one's time to generate additional research results that could then increase their chances of publishing in highly ranked journals in the future. Furthermore, academic researchers may be less willing to openly disclose their newest findings at scientific conferences, fearing that valuable information that has yet to be published may fall into the hands of the competition. Similarly, they may be more likely to refrain from responding to requests for both unpublished and published knowledge from other academic researchers, as they worry that their competitors may gain an advantage in their research projects and ultimately publish the related findings before them:

H5. The level of perceived competition in the scientific field is positively related to the extent of knowledge-sharing restrictions in the content and timing of publications coauthored with other academic researchers, public presentations of research results and exchange of published and unpublished knowledge.

How researchers behave with respect to knowledge sharing may also be related to the general sharing climate in their immediate working environment. According to Perkmann et al. (2013), the investigation of the role of local norms in individuals' behavior represents a challenging research opportunity in studying academia-industry interactions. Following previous research (Fullwood and Rowley, 2017; Haas and Park, 2010; Wang and Noe, 2010), this study argues that the attitudes, behaviors and actions of leaders and managers of research groups define the common sharing norms of the group and individual researchers within the group. If their supervisors and colleagues support restrictive practices in knowledge sharing, it is expected that academic researchers will be more likely to exhibit restrictive behaviors in knowledge sharing themselves.

This study hypothesizes that the role of the institutional sharing climate is significantly related to the direct exchange of published and unpublished knowledge (information, data and materials) with other researchers, public presentation and the content and timing of publications co-authored with other academic researchers. With these types of knowledge sharing, researchers directly and personally interact with other research groups, which is why the influence of co-workers in the laboratory is expected to be of significance in researchers' sharing decisions:

H6. The perceived institutional climate in support of sharing is likely to be negatively related to knowledge-sharing restrictions in terms of the direct exchange of published and unpublished knowledge, public presentations and the content and timing of publications co-authored with other academic researchers.

The proposed conceptual framework of the study is shown in Figure 1.

\section{Data and methods}

\subsection{Sample and data}

The survey data were collected for this study from a sample of life science researchers affiliated with universities and other non-profit research institutions, because prior research suggests that life scientists are the group most active in academia-industry knowledge transfer (Stuart and Ding, 2006). Most of the respondents (23\%) performed research in the field of diagnostic tools, therapies and public health; $12 \%$ were involved in evolutionary, population and environmental biology research, whereas $11.8 \%$ belonged to the neurosciences and neural disorders field, according to the categorization of the European Research Council (ERC). 


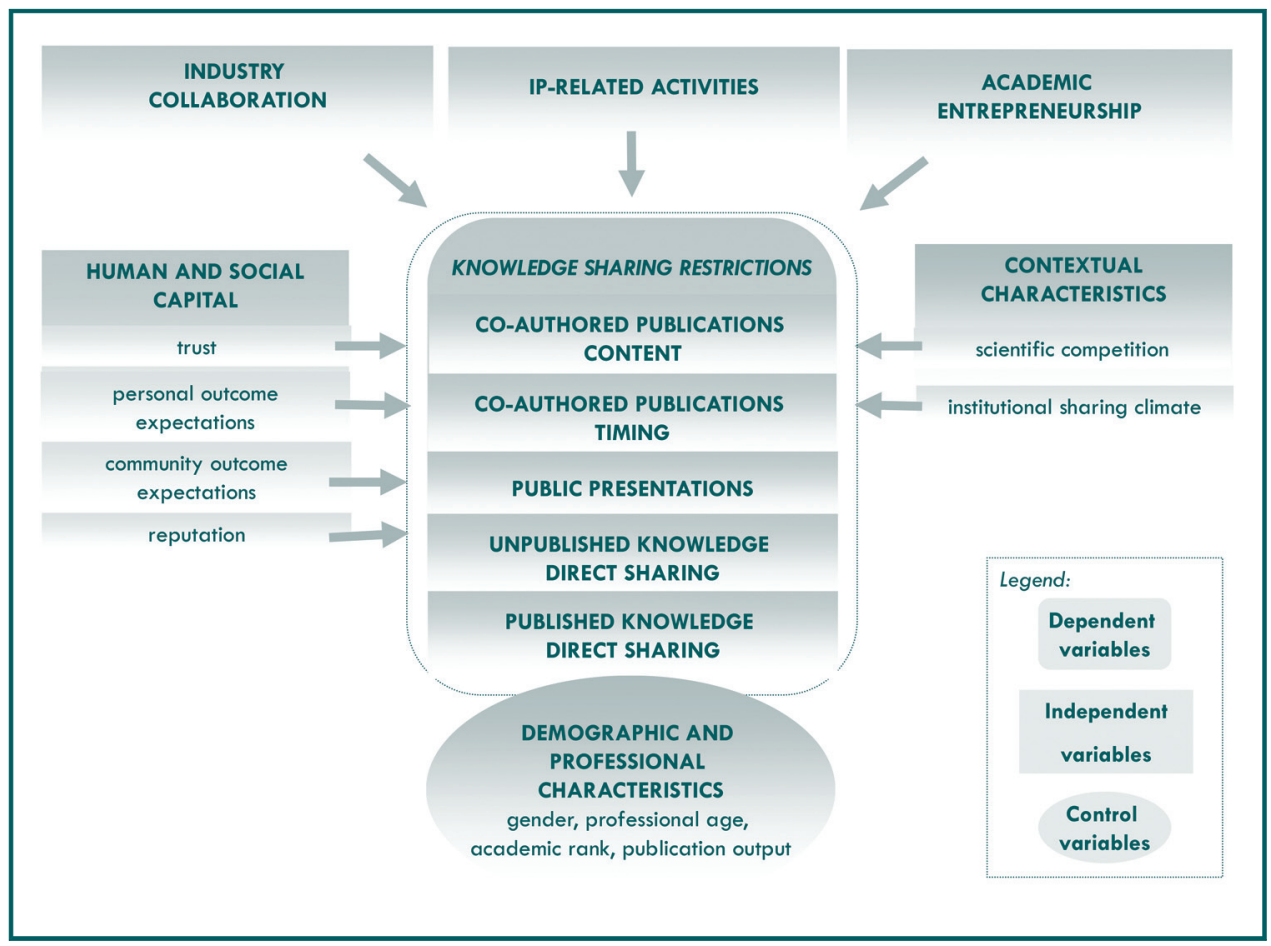

The sample population included all life scientists with a doctoral degree based on the evidence of the Ministry of Science and Education in Croatia, and comprised 2,956 unique names. These data were complemented by a manual search of e-mail addresses. The e-mail addresses of 406 scientists could not be found, and an internet search revealed that they had exited scientific activity. The final version of the survey was e-mailed to 2,550 respondents via the online survey platform LimeSurvey in June-July 2016. In total, 255 e-mail invitations to participate in the survey were returned as undeliverable, and 21 respondents refused to participate. Out of the 2,274 remaining respondents, 456 or $20.05 \%$ partially completed the survey. In the final analysis, 212 surveys were included: 209 surveys that were fully completed and an additional three surveys that were over $70 \%$ complete.

To test for potential non-response bias, the answers of early and late respondents were compared in terms of the dependent variables of knowledge-sharing restrictions, following Armstrong and Overton's (1977) recommendations using the Kolmogorov-Smirnov nonparametric test. The responses of the first $20 \%$ of respondents were compared with those of the last $20 \%$ of respondents and no significant differences were found between the two groups for any of the dependent variables. Also, the scientific productivity data were compared between scientists from the response and non-response group. This step included a random selection of 50 researchers from the response group and 50 researchers from the non-response group and, using the Web of Science and Croatian Scientific Bibliography (CROSBI) databases, collection of the information on the number of their publications in the past five years. No significant difference in publication productivity between the two groups was found (10.24 respondent vs 9.06 non-respondent publications). Finally, scientists from the response and non-response groups were also compared with respect to gender (62\% female in both groups) and age (48.38 respondent vs 51.34 non-respondent) and no significant differences were found between the two groups. 


\subsection{Measures}

The survey instrument was developed based on the literature review, prior surveys and semi-structured interviews with 38 key informants (scientists, entrepreneurs and technology transfer specialists). To validate the instrument, pilot interviews with five scientists were conducted, and the reliability and validity of the scales were calculated for interval measures.

3.2.1 Dependent variables. With the survey, this paper investigated five different types of knowledge-sharing restrictions in the life sciences academic communities; these were essentially the dependent variables. The co-authored publication content restrictions variable measured the number of articles published in the past five years in co-authorship with other research groups from the academic sector in which the respondents had had to exclude some relevant content (research results) from the manuscript. To measure coauthored publication timing restrictions, respondents were asked to estimate in how many of the articles published in the past five years in co-authorship with other research groups from the academic sector they had delayed publication by more than six months.

Knowledge sharing through presentations (oral or poster) could occur at seminars in other departments of the respondents' institution, at other academic institutions or at professional meetings. To measure presentation restrictions, the survey asked the respondents how many presentations had involved them intentionally excluding some relevant content (unpublished research results), either during the presentation or during the question and answer session with the audience.

Knowledge-sharing restrictions in direct exchange of knowledge refers to the number of times the respondents had denied (explicitly rejected or ignored) requests for information (e.g. regarding laboratory techniques or protocols, genetic sequences or protein structures), data (e.g. database or software) and materials (e.g. reagents, chemical compounds, cell lines, tissues, model organisms, proteins, genes, plasmids) from other academic researchers informally, via e-mail or personally (without a contractual relationship) in the past five years following research by Blumenthal et al. (2006), Walsh and Huang (2014) and Thursby et al. (2018). In multivariate analyses, two variables were constructed: one measuring the number of denials for unpublished information and materials, and the other measuring the number of denials for published information and materials. Therefore, all dependent variables were measured as count variables.

3.2.2 Independent variables. Academia-industry knowledge transfer activities. The extent of respondents' involvement in academia-industry knowledge transfer was measured with three variables: Industry collaboration, Intellectual property-based activities and Academic entrepreneurship. To construct these variables, the study drew from the prior literature investigating the impact of knowledge transfer on knowledge sharing (Walsh et al., 2007; Campbell et al., 2000; Campbell et al., 2002; Campbell et al., 2004; Walsh and Huang, 2014), as well as the determinants of researchers' involvement in academia-industry knowledge transfer (Abreu and Grinevich, 2013; Aschhoff and Grimpe, 2014; D'Este and Perkmann, 2011; Haeussler and Colyvas, 2011). Next, we conducted in-depth semistructured interviews, asking key informants to elaborate on the specific academia-industry knowledge-transfer activities they had been involved in. Based on the information provided, we identified a range of possible types of academia-industry knowledge transfer. Through the analysis of literature and interview responses, we produced 20 survey questions corresponding to different types of academia-industry knowledge transfer that respondents could have been involved in, either as a team leader or as a team member, in the past five years. The 20 questions were grouped into three categories of academia-industry knowledge-transfer activities: industry collaboration (eight questions), intellectual propertybased activities (six questions) and academic entrepreneurship (six questions). The examples of questions are as follows: How many companies have you consulted (independently or as an advisory board member)? In how many university-industry joint 
research projects (FP7, Horizon 2020 or similar) have you been involved? (Category 1); How many patent applications have been submitted for the inventions with you as an inventor or co-inventor? How many licensing agreements have been signed by you or your institution based on your non-patented research results? (Category 2); In how many business plans or other activities related to starting a new firm have you been involved? How many companies (related to your research work) have you founded? (Category 3). The composite continuous variables Industry collaboration, Intellectual property-based activities and Academic entrepreneurship were constructed by the summation of the responses to all questions in each academia-industry knowledge-transfer activity category.

3.2.3 Sharing motivations, contextual factors. Personal outcome expectations, community-related outcome expectations, trust, reputation and institutional sharing climate were measured using multiple items. All measurement items were adapted from subscales already validated in previous literature (Bock et al., 2005; Chiu et al., 2006; Fullwood et al., 2013; Haeussler, 2011), and minor modifications were made to account for the specific context of knowledge sharing in the academic community. Table 1 shows Cronbach's reliability estimates for each construct, as well as the means, standard deviations and loadings for all items following confirmatory factor analysis (Pallant, 2001; Tabachnick and Fidell, 2019). This analysis was performed using AMOS 26 software with maximum-likelihood estimation procedures. The results obtained with five factors indicated an adequate model fit with the data (the Chi-square value normalized by degrees of freedom was 2.513, NFI was 0.909 and CFI 0.942). All construct items had positive, high and significant coefficients. Composite reliability was over 0.8 for all constructs. In addition to composite reliability, convergent validity was examined by average variance extracted (AVE). AVE scores ranged from 0.67 to 0.90 , which is above the recommended threshold of 0.5 for each construct (Fornell and Larcker, 1981). To assess the discriminant validity of each construct, the square root of its AVE was compared with all correlation coefficients between constructs. Because the values of the square root of AVE exceeded the values of correlation coefficients, the discriminant validity test was estimated as acceptable. The results of analysis are shown in Appendix, where the diagonal values indicate the square root of AVE and other values refer to the correlations between constructs.

To assess the role of the sharing context, the Competition variable was measured as a response (on a scale from 1 to 5 , where 1 stands for "not at all competitive" and 5 stands for "extremely competitive") to the question: "How would you characterize the overall level of competition for recognition or scientific priority in your specific area of research?", following Blumenthal et al. (2006), Vogeli et al. (2006) and Haeussler et al. (2014).

3.2.4 Control variables. The control variables included gender, academic rank, professional age (total number of years of employment) and scientific output (number of publications in Web of Science database in the past five years).

\section{Results}

\subsection{Descriptive analyses}

The summary statistics for variables used in the multivariate analysis are shown in Table 2. The majority of the respondents (64\%) were female. The largest proportion of them (36\%) held a position as Assistant Professor or equivalent, whereas 27\% were Full Professors or equivalent and $24 \%$ were Associate Professors or equivalent. Most of the respondents (84\%) were affiliated with only one institution. Their most frequently reported affiliations were pre-clinical departments at higher education institutions (34\%), public health institutions hospitals, clinics (24\%), clinical departments at higher education institutions $(20 \%)$ and public research institutes (17\%). On average, the respondents had 22.5 years of professional experience, out of which 20.6 were in the non-profit sector and 18.2 were in the 


\begin{tabular}{|c|c|c|c|c|}
\hline Construct & Measure & Mean & St. dev. & Loading \\
\hline \multicolumn{5}{|c|}{ Personal outcome expectations (POEXP) composite reliability $=0.920$} \\
\hline POE1 & $\begin{array}{l}\text { Sharing my knowledge will help me to make friends with other researchers in the } \\
\text { academic community }\end{array}$ & 5.36 & 1.522 & 0.726 \\
\hline POE2 & Sharing my knowledge will give me a feeling of happiness & 5.21 & 1.746 & 0.699 \\
\hline POE3 & $\begin{array}{l}\text { Sharing my knowledge can build up my reputation with other researchers in the } \\
\text { academic community }\end{array}$ & 5.33 & 1.572 & 0.881 \\
\hline POE4 & Sharing my knowledge will give me a sense of accomplishment & 5.19 & 1.647 & 0.853 \\
\hline POE5 & $\begin{array}{l}\text { Sharing my knowledge will strengthen the tie between other researchers in the } \\
\text { academic community and me }\end{array}$ & 5.66 & 1.334 & 0.876 \\
\hline POE6 & $\begin{array}{l}\text { Sharing my knowledge will enable me to gain better cooperation from the outstanding } \\
\text { members in the academic community }\end{array}$ & 5.41 & 1.456 & 0.857 \\
\hline \multicolumn{5}{|c|}{ Community-related outcome expectations (COEXP) composite reliability $=0.971$} \\
\hline COE1 & $\begin{array}{l}\text { Sharing my knowledge will be helpful to the successful functioning of the academic } \\
\text { community }\end{array}$ & 6.02 & 1.269 & 0.942 \\
\hline COE2 & $\begin{array}{l}\text { Sharing my knowledge would help the academic community continue its operation in } \\
\text { the future }\end{array}$ & 6.01 & 1.233 & 0.969 \\
\hline COE3 & $\begin{array}{l}\text { Sharing my knowledge would help the academic community accumulate or enrich } \\
\text { knowledge }\end{array}$ & 6.14 & 1.178 & 0.964 \\
\hline COE4 & Sharing my knowledge would help the academic community grow & 6.04 & 1.338 & 0.919 \\
\hline \multicolumn{5}{|c|}{ Trust (TRUST) composite reliability $=0.963$} \\
\hline TR1 & $\begin{array}{l}\text { Members of the academic community to which I belong will not take advantage of } \\
\text { others even when the opportunity arises }\end{array}$ & 3.48 & 1.702 & 0.833 \\
\hline TR2 & $\begin{array}{l}\text { Members of the academic community to which I belong will always keep the promises } \\
\text { they make to one another }\end{array}$ & 3.47 & 1.613 & 0.939 \\
\hline TR3 & $\begin{array}{l}\text { Members of the academic community to which I belong would not knowingly do } \\
\text { anything to disrupt the communication }\end{array}$ & 3.49 & 1.754 & 0.935 \\
\hline TR4 & Members of the academic community to which I belong behave in a consistent manner & 3.71 & 1.675 & 0.933 \\
\hline TR5 & $\begin{array}{l}\text { Members of the academic community to which I belong are truthful in dealing with one } \\
\text { another }\end{array}$ & 3.44 & 1.698 & 0.941 \\
\hline \multicolumn{5}{|c|}{ Reputation (REPUT) composite reliability $=0.916$} \\
\hline REP1 & $\begin{array}{l}\text { How important for your reputation among peers is the number of articles published in } \\
\text { peer reviewed journals? }\end{array}$ & 4.09 & 0.972 & 0.847 \\
\hline REP2 & $\begin{array}{l}\text { How important for your reputation among peers is the impact factor of the journals } \\
\text { where your articles appear? }\end{array}$ & 3.97 & 1.078 & 0.927 \\
\hline REP3 & $\begin{array}{l}\text { How important for your reputation among peers is the number of citations published } \\
\text { articles receive? }\end{array}$ & 3.91 & 1.105 & 0.979 \\
\hline REP4 & How important for your reputation among peers are scientific awards? & 3.60 & 1.070 & 0.663 \\
\hline \multicolumn{5}{|c|}{ Institutional sharing climate (ISCLIM) composite reliability $=0.805$} \\
\hline ISC1 & $\begin{array}{l}\text { My direct supervisor thinks that I should share my knowledge with other researchers in } \\
\text { the academic community }\end{array}$ & 3.43 & 1.215 & 0.850 \\
\hline ISC2 & $\begin{array}{l}\text { My colleagues in the research group think I should share knowledge with other } \\
\text { researchers in the academic community }\end{array}$ & 3.58 & 1.040 & 0.803 \\
\hline
\end{tabular}

current institution of employment. They directly supervised on average 9.5 personnel, 4.9 of which were research personnel. The mean number of publications for the past five years was 11.3.

The results of the data analysis showed that $68 \%$ of the academic researchers had been involved in at least one type of academia-industry knowledge transfer, yet with an overall low level of involvement. Most activities were reported in the industry collaboration category, on average 10.2 activities in the past five years. Presentations for the business sector were the most frequently reported type of academia-industry knowledge transfer in this category, followed by publications in co-authorship with the business sector and consulting for enterprises. 
Table 2 Summary statistics (dependent, independent and control variables)

\begin{tabular}{lrrrrr} 
Variable & No. obs. & Mean & St. dev. & Min & Max \\
\hline Dependent variables & & & & & \\
Co-authored publication content restrictions [COCOO] & 212 & 0.264 & 0.824 & 0 & 5 \\
Co-authored publication timing restrictions [COTIO] & 212 & 0.467 & 2.854 & 0 & 40 \\
Presentation restrictions [PRESREO] & 212 & 1.566 & 13.795 & 0 & 200 \\
Unpublished knowledge-sharing restrictions [UNPRED] & 212 & 0.476 & 2.981 & 0 & 40 \\
Published knowledge-sharing restrictions [PRED] & 212 & 1.066 & 4.293 & 0 & 45 \\
Independent variables & & & & & \\
Academic-industry knowledge transfer activities & & & & & \\
Industry collaboration [INDCOL] & 212 & 10.208 & 22.595 & 0 & 169 \\
Intellectual property-based [IPBASE] & 212 & 0.839 & 4.027 & 0 & 46 \\
Academic entrepreneurship [ACAENT] & 212 & 1.669 & 7.910 & 0 & 100 \\
Sharing motivations and values & & & & & \\
Personal outcome expectations [POEXP] & & & & 7 \\
Community-related outcome expectations [COEXP] & 212 & 5.362 & 1.311 & 1 & 7 \\
Trust [TRUST] & 212 & 6.052 & 1.205 & 1 & 7 \\
Reputation [REPUT] & 212 & 3.517 & 1.575 & 1 & 7 \\
Sharing context & 211 & 3.893 & 0.945 & 1 & 5 \\
Competitiveness perception [COMP] & & & & & \\
Institutional sharing climate [ISCLIM] & 211 & 3.431 & 0.995 & 1 & 5 \\
Control variables & 211 & 3.507 & 1.035 & 1 & 5 \\
Research productivity [PUBQTY] & & & & & \\
Academic rank - Full Professor [RANK] & & & & \\
Professional age [PRAGE] & 212 & 11.264 & 10.536 & 0 & 82 \\
Gender - female [GEN] & 209 & 0.268 & - & - & - \\
& 209 & 22.536 & 8.165 & 5 & 42 \\
& 212 & 0.637 & - & 0 & 1
\end{tabular}

Intellectual property-based academia-industry knowledge transfer activities were conducted very rarely, on average only 0.84 per respondent. The most frequently reported types of activity in this category were negotiations over rights and commercialization of inventions.

The involvement of researchers in the third category of academia-industry knowledge transfer, academic entrepreneurship, was also very low, with an average of 1.67 activities per respondent. The respondents most frequently reported experience with products directly based on their research results under regulatory review and on the market, whereas establishment, co-ownership and management of spin-off companies were the least common.

Knowledge-sharing restrictions most frequently occurred during public presentations and in direct exchange of published and unpublished knowledge. The respondents presented their research work at on average 12 occasions during the past five years. On an average of 1.6 occasions (or $13 \%$ ), they intentionally withheld some relevant unpublished content from the audience. The most requests they received were for published materials, data and information from other researchers (on average, 18.7 in the past five years), while received requests for unpublished knowledge were fewer (on average, 4.9). At the same time, higher sharing restrictions were imposed with unpublished information, data and materials than with published knowledge.

\subsection{Results from econometric analyses}

To test the research hypotheses, the study used five regression models predicting the various types of knowledge-sharing restrictions. Considering that the dependent variables did not follow a normal distribution, the models were estimated using a negative binomial 
regression, which accounts for the overdispersion of count variables (Hausman et al., 1984; Walsh et al., 2007). Table 3 shows the results of the analyses performed in SPSS Statistics software. An incidence rate ratio (IRR) greater than one indicates a positive effect of the regressor on the level of sharing restrictions, whereas a ratio less than one indicates a negative effect.

In accordance with the first group of hypotheses, involvement in academia-industry knowledge transfer was associated with a greater extent of knowledge-sharing restrictions. However, the results differed depending on the academia-industry knowledge-transfer category in question. Industry collaboration was significantly associated with all investigated types of knowledge-sharing restrictions. For every one-unit increase in the level of interaction with industry (e.g. consulting the business sector, holding presentations for the industry or engaging in industry-sponsored research), there was a $2 \%$ increase in content restrictions with co-authored publications, $2 \%$ increase in timing restrictions with coauthored publications, $2 \%$ increase in sharing restrictions during presentations, $2 \%$ increase in restrictions on sharing unpublished data and materials and $1 \%$ increase in restrictions on sharing published data and materials. Thus, the results show support for H1a.

Next, for a one-unit increase in the level of intellectual property-based academia-industry knowledge-transfer activities, there was a 13\% increase in co-authored publication timing restrictions $(p<0.05)$ and a $9 \%$ increase in the level of sharing restrictions during public presentations $(p<0.1$ ), supporting H1b. Surprisingly, intellectual property-based academia-industry knowledge transfer was also (although weakly significantly) negatively associated with restrictions on sharing unpublished data and materials, which means that the more the researchers were involved in patenting and licensing activities, the less they denied other academic researchers access to their research results. Intellectual propertybased activities were not significantly associated with other forms of knowledge-sharing restrictions.

Table 3 Negative binomial regression analyses of knowledge-sharing restrictions

\begin{tabular}{lcccrr} 
Variable & COCOO & COTIO & PRESREO & UNPRED & PRED \\
\hline INDCOL & $1.015^{*}(0.0065)$ & $1.015^{*}(0.0064)$ & $1.020^{* *}(0.0053)$ & $1.019^{*}(0.0094)$ & $1.014^{*}(0.0054)$ \\
IPBASE & $0.975(0.0698)$ & $1.131^{*}(0.061)$ & $1.092^{\dagger}(0.0521)$ & $0.513^{\dagger}(0.3722)$ & $0.924(0.0556)$ \\
ACAENT & $1.020(0.0362)$ & $0.966(0.0338)$ & $0.974(0.0281)$ & $1.007(0.0604)$ & $1.051^{\dagger}(0.0265)$ \\
POEXP & $0.695^{*}(0.1825)$ & $0.632^{*}(0.1867)$ & $0.776^{*}(0.1220)$ & $0.576^{* *}(0.156)$ & $1.344^{*}(0.1167)$ \\
COEXP & $1.173(0.1909)$ & $1.301(0.1888)$ & $1.304^{\dagger}(0.1374)$ & $1.409^{\dagger}(0.1931)$ & $0.942(0.1254)$ \\
TRUST & $0.862(0.1331)$ & $0.5898^{* *}(0.1583)$ & $0.837^{\dagger}(0.1019)$ & $0.802^{\dagger}(0.1235)$ & $0.968(0.0845)$ \\
REPUT & $0.916(0.2056)$ & $0.671^{*}(0.1679)$ & $1.200(0.1576)$ & $1.246(0.2309)$ & $0.904(0.1429)$ \\
COMP & $1.056(0.1984)$ & $1.311(0.2019)$ & $1.431^{*}(0.1523)$ & $0.967(0.2029)$ & $1.374^{*}(0.1401)$ \\
ISCLIM & $0.733(0.2010)$ & $0.576^{* *}(0.1909)$ & $0.760^{\dagger}(0.1481)$ & $1.048(0.191)$ & $0.858(0.1327)$ \\
PUBQTY & $1.013(0.0164)$ & $1.019(0.0158)$ & $1.026^{*}(0.0127)$ & $0.926^{* *}(0.0288)$ & $0.963^{* *}(0.0144)$ \\
PRAGE & $0.928^{* *}(0.0273)$ & $0.954^{*}(0.0236)$ & $0.957^{*}(0.0188)$ & $0.994(0.0225)$ & $1.062^{* *}(0.0165)$ \\
GEN & $0.665(0.3553)$ & $1.471(0.3745)$ & $0.887(0.2761)$ & $0.346^{* *}(0.3256)$ & $1.057(0.2252)$ \\
RANK (Full Professor $=$ ref.) & $0.655(0.4625)$ & $1.179(0.4631)$ & $0.795(0.3351)$ & $0.743(0.504)$ & $0.945(0.2896)$ \\
N & 209 & 209 & 209 & 209 & 209 \\
Pearson Chi-square (value/df) & 1.531 & 1.365 & 1.841 & 3.285 & 4.971 \\
Omnibus test (sig.) & 0.000 & 0.000 & 0.000 & 0.000 & 0.000
\end{tabular}

Notes: Estimates shown as IRRs (incidence rate ratios); standard errors in parentheses; ${ }^{* *} p<0.01,{ }^{*} p<0.05,{ }^{\dagger} p<0.1$. COCOO, coauthored publication content restrictions; COTIO, co-authored publication timing restrictions; PRESREO, presentation restrictions; UNPRED, unpublished knowledge-sharing restrictions; PRED, published knowledge-sharing restrictions; INDCOL, industry collaboration; IPBASE, intellectual property-based; ACENT, academic entrepreneurship; POEXP, personal outcome expectations; COEXP, community-related outcome expectations; TRUST, trust; REPUT, reputation; COMP, competitiveness perception; ISCLIM, institutional sharing climate; PUBQTY, research productivity; RANK, academic rank - Full Professor; PRAGE, professional age; GEN, gender 
Involvement in academic entrepreneurship-related activities was significantly associated $(p<0.1)$ only with restrictions on sharing published data and materials, with $5 \%$ more restrictions for every unit increase in the level of business activities. Thus, the results partially support $\mathrm{H} 1 \mathrm{C}$, as a significant coefficient was obtained for published but not unpublished knowledge sharing.

Congruent with $\mathrm{H} 3 \mathrm{a}$, personal outcome expectations were significantly negatively associated with content restrictions with co-authored publications (30\% decrease), timing restrictions with co-authored publications (37\% decrease), sharing restrictions during presentations (22\% decrease) and restrictions with sharing unpublished knowledge (42\% decrease). Yet, for personal outcome expectations in the model predicting restrictions on sharing published data and materials, the coefficient pointed to an opposite effect: for a one-unit increase in personal outcome expectations, there was a $34 \%$ increase in the level of restrictions. Interestingly, the community-related outcome expectations variable was not significantly associated with knowledge-sharing restrictions, with the exception of marginally significant positive coefficients for the restrictions during presentations and for unpublished knowledge sharing, which is why H3b cannot be supported.

Trust was significantly negatively associated with three types of knowledge-sharing restrictions (partial support for H2): timing restrictions with co-authored publications ( $41 \%$ decrease in the level of restrictions for every unit increase), sharing restrictions during presentations (16\% decrease) and restrictions on sharing unpublished knowledge (20\% decrease). Reputation was significantly associated with co-authored publication timing restrictions (33\% decrease), which is why the results show only partial support for $\mathrm{H} 4$.

In accordance with previous studies and in line with $\mathrm{H} 5$, the analysis showed that the higher the perception of competitiveness of the research field, the higher the level of knowledge-sharing restrictions: for example, for a unit increase in the competition variable, there was a $43 \%$ increase in sharing restrictions during presentations. Institutional sharing climate was significantly associated with timing restrictions with coauthored publications $(p<0.01)$ and restrictions during public presentations $(p<0.1)$, where the more supportive the institutional environment (supervisor and colleagues) was toward sharing, the fewer restrictions there were. Although hypothesized, no significant relationship was found between the institutional sharing climate and restrictions on direct exchange of published and unpublished knowledge. Thus, the results show partial support for $\mathrm{H} 6$.

As for the control variables included in the regression, scientific output, measured by the number of publications in the past five years, was significantly positively related to the extent of sharing restrictions during presentations and significantly negatively related to restrictions on sharing unpublished and published data and materials. Professional age was significantly negatively associated with content and timing restrictions with co-authored publications and sharing restrictions during presentations, where the older the researcher, the less he or she restricts knowledge sharing. On the other hand, the older the researcher, the more he or she restricts the direct sharing of published data and materials. Gender and academic rank were not significantly associated with any of the dependent variables, with the exception of restrictions on sharing unpublished data and materials, which were more present with male researchers. Table 4 summarizes the results of the hypothesis testing.

\section{Discussion and conclusions}

This study makes several important contributions. The results correspond with prior findings (Blumenthal et al., 1997; Campbell et al., 2002; Czarnitzki et al., 2015; Walsh et al., 2007), supporting the idea that the involvement of a researcher in academia-industry knowledge transfer is positively associated with his/her tendency to restrict knowledge sharing. Going 
Table 4 Summary of results of the hypothesis testing

Knowledge-sharing restriction

Hypothesis Co-author content Co-author delay Presentation Unpublished exchange

Published exchange

\begin{tabular}{|c|c|c|c|c|c|c|c|}
\hline 1a (Industry collaboration) & YES & YES & YES & YES & & YES & \\
\hline $1 b$ (IP-related activities) & - & YES & YES & & - & & - \\
\hline 1c (Academic entrepreneurship) & - & - & - & NO & & YES & \\
\hline 2 (Trust) & NO & YES & YES & YES & & NO & \\
\hline 3a (Personal outcome expectations) & YES & YES & YES & YES & & NO & \\
\hline $3 b$ (Community outcome expectations) & NO & NO & NO & NO & & NO & \\
\hline 4 (Reputation) & NO & YES & NO & NO & & NO & \\
\hline 5(Competition) & NO & NO & YES & NO & & YES & \\
\hline 6 (Institutional sharing climate) & NO & YES & YES & NO & & NO & \\
\hline
\end{tabular}

Notes: YES, hypothesis supported; NO, hypothesis not supported; -, effect not hypothesized

beyond existing knowledge (Nelson, 2016), this study unveils that the nature of such a relationship depends on the type of academia-industry knowledge-transfer activity and the type of knowledge sharing. Because contracts with industry usually include confidentiality provisions, researchers who actively collaborate with industry are more likely to omit relevant content from publications in co-authorship with other academic researchers; delay their publications in co-authorship with other academic researchers; exclude relevant content during public presentations of their research results; and deny requests for access to their unpublished and published data and materials.

In line with the hypotheses proposed, the results showed that the relationship between intellectual property-based knowledge-transfer activities and knowledge-sharing restrictions was significant and positive. This finding may be because of the demands of current legislative frameworks in most countries, which stipulate that inventions at work are owned by the employer. Most academic institutions have formally established TTOs, which are responsible for receiving invention disclosures, evaluating the commercial potential of inventions, suggesting the appropriate intellectual property protection mode and managing intellectual property, including negotiations with industry. If these TTOs are relatively inexperienced, it will take them more time to review the disclosed research results, assess their patentability and prepare the patent application. During this time, the researchers must keep their findings undisclosed to the public, and so they delay publishing their research results [also discussed by Thompson et al. (2018)] and restrict the content of their public presentations. A somewhat unexpected finding was the significant and negative coefficient related to the restrictions on sharing unpublished information, data and materials. One possible explanation for this finding is that only a portion of academic researchers' results is covered by patents or licensing agreements or under consideration for intellectual property protection; therefore, general access to their research results, data and materials is not negatively affected by their involvement in intellectual propertyrelated knowledge-transfer activities.

The results also showed that the involvement in academic entrepreneurship-related activities was significantly associated with certain knowledge-sharing restrictions (as far as published data and materials are concerned). This finding may be because of the fact that those researchers who are actively engaged in commercial activities may have less time to respond to peers' requests for their research materials and data [see also Shibayama et al. (2012)]. Furthermore, their products may already be on the market and no longer accessible to other academic researchers on a free-of-charge, collaborative basis.

Of all the independent variables used to measure researchers' motivations to share, personal outcome expectations were found to be the most important predictor of knowledge-sharing restrictions. The more researchers discover that sharing brings them personal gains in terms of feelings of happiness, accomplishments and closer ties with 
other researchers in the academic community, the less they will restrict their knowledge sharing. This is in line with previous studies on knowledge sharing in other communities (Chiu et al., 2006).

Trust, as a component of a researcher's social capital, was significantly negatively associated with restrictions on the direct exchange of unpublished information, data and materials. Trust was also significantly related to timing restrictions in the case of coauthored publications and sharing restrictions during presentations. These findings support the predictions of this research based on prior literature investigating the relationship between trust and knowledge sharing in different organizations (Connelly et al., 2012; Wang and Noe, 2010; Zhu, 2017). For example, if academic researchers generally perceive an academic community as truthful and reliable, they will have greater trust in their audience and thus will be less likely to engage in sharing restrictions during public presentations of their scientific results. Reputation among peers was an important predictor of restrictions in only one investigated type of knowledge sharing in the academic community. The more importance academic researchers attach to their number of awards and publications, their impact and citations, the less they delay the publication of their research results coauthored with other research teams. This finding complements those of previous studies (Haeussler et al., 2014) showing that sharing knowledge with a general audience (via publications) has greater relevance for one's reputation than specific, direct sharing with other researchers.

Finally, the institutional context must always be considered when interpreting the study results from examinations of academia-industry collaborations (Walsh and Huang, 2014). Scientific competition was identified as an important predictor of sharing restrictions when it comes to public presentations and direct sharing of published data and materials with other researchers. Although it was expected that the institutional climate in support of sharing would be negatively related to knowledge-sharing restrictions in the exchange of published and unpublished knowledge (information, data and materials), it seems that, in the context of this study, the sharing behavior of their immediate supervisors and colleagues did not play a significant role in the respondents' sharing decisions. There is prior evidence showing that information withholding is influenced by the behaviors of life scientists' peers and superiors (Haas and Park, 2010); however, that study relied on an etic (observerdefined) approach in identifying reference group members (peers and superiors) and was limited to the investigation of sharing restrictions with published research only, which is why further research is needed to clarify the role of the institutional sharing climate in knowledge sharing in science.

Overall, this study has several important implications for theory and practice. The main theoretical contribution of the study is that it considers the heterogeneity of different types of academic knowledge transfer and knowledge sharing in conceptualizing and testing the relationship between knowledge transfer and knowledge sharing in academia-industry interactions. By separately analyzing the effects of different knowledge-transfer activities on various types of sharing restrictions, this study acknowledges the complexity of academia-industry interactions at the level of individual researchers. In this way, this research makes an important contribution to the body of knowledge on the economic aspects of academic researchers' behavior (Campbell et al., 2000). This study also contributes to the field of knowledge management and sharing research, as it takes into account a broad range of personal and context-specific predictors of individuals' knowledge-sharing behavior in academia. The study results suggest that policy instruments should foster the development of network connections among researchers, since the social capital associated with such ties facilitates knowledge sharing within the community - a finding that is aligned with the study of Levin and Cross (2004).

Drawing from the findings of this study, it is possible to advise policymakers on how to design measures to support technology and knowledge-transfer activities in practice. This 
paper shows that knowledge-transfer activities can be positively associated with knowledge-sharing restrictions, even in settings with a relatively low level of researcher engagement in academia-industry knowledge transfer. This suggests that academia-industry knowledge transfer has a meaningful impact on the science system, including the patterns of knowledge exchange and the scientific norms of sharing. Furthermore, it seems that not all types of academia-industry knowledge transfer are associated with all types of knowledge-sharing restrictions. Therefore, instead of promoting academia-industry knowledge and technology transfer in a uniform and unconditional way, policymakers at academic institutions should engage in a detailed analysis of the scientific interests of academic researchers and the characteristics of their inventions before establishing any contractual relationships with industry or proceeding with the commercialization of research results through patenting, licensing or spin-offs. For example, adequate policies should protect doctoral researchers from the contractual provisions of industry contracts that prevent them from publicly disclosing their thesis results. Another recommendation is to conduct a careful prior assessment of the potential societal and economic impacts of certain inventions. If it is expected that the invention will mainly be used for basic academic research and teaching purposes, it may make more sense to pursue broad dissemination rather than commercial exploitation on exclusionary terms.

Moreover, the study findings suggest that, when examining the factors hindering open knowledge sharing in academic communities, policymakers should not solely consider the interactions of academic researchers with industry and their commercial activities. Instead, they should account for other factors, such as researchers' personal characteristics and motivations, as well as context-specific determinants of knowledge-sharing restrictions. Such an approach will facilitate the design of science policies that will stimulate academia-industry knowledge transfer, while upholding the characteristics of the open science system. Many science funding agencies and programs (for example, US National Institutes of Health, European Commission's Horizon 2020) have already made it mandatory for researchers to open their results (Andreoli-Versbach and Mueller-Langer, 2014). The European Commission's open science policy initiatives are likely to play an even more prominent role in coming years, considering the focus on FAIR (findable, accessible, interoperable and reusable) data, open and collaborative research and sharing of research results as early as possible in the research process. Upholding these principles is facilitated by developments in information and communications technologies and related infrastructures, including repositories such as the European Open Science Cloud (EOSC) (European Commission, 2020).

In addition, this study uncovers the role of individual and contextual characteristics and motivations in knowledge sharing; for example, trust, personal outcome expectations and institutional sharing climate. Taking these factors into account, policy measures should be directed toward the promotion of a knowledge-sharing culture (Fullwood and Rowley, 2017) by providing young researchers with early compulsory training on the importance and benefits of open sharing - both for themselves and for the scientific community as a whole. Research funding programs should also support the training of researchers in implementing open science procedures. In addition, academic promotion systems should formally incentivize researchers to openly share their research findings. In practice, the European Commission's policies set the general framework for introducing new ways of funding, evaluating and rewarding researchers for adhering to open science principles and intensifying collaboration with other research groups (e.g. by including open science in the award criteria of research grants or with new metrics for research quality and impact). However, national and organizational efforts are needed to adopt, implement and monitor specific measures aimed at reducing the barriers to free and open knowledge sharing in academia 


\section{Limitations and future research avenues}

The first limitation of the study is related to the use of interviews and a questionnaire survey for the empirical part of the research on the relationship between knowledge transfer and knowledge sharing in academia-industry interactions. A cross-sectional design and selfreported measures in questionnaire surveys present major drawbacks compared to scientometrics (Azoulay et al., 2006). Scientometrics have been used extensively in the literature relying on co-authorship of scientific papers to analyze knowledge exchange among researchers, both within and across individual companies and academic research groups, as well as to investigate the social networks of academic scientists (Murray and Stern, 2007; Rosell and Agrawal, 2009). At the same time, the use of questionnaires and interviews yields better insights into the causes and effects of particular behaviors (Campbell et al., 2002; Walsh et al., 2007), which was one of the goals of this study.

The second limitation is related to the use of survey responses that were collected in 2016 for the empirical analysis. More recent survey data collected for future research may provide somewhat different insights into the determinants of knowledge-sharing restrictions in academic communities.

The third concern of this empirical approach involves a potential reverse causality problem in the empirical testing of determinants of knowledge-sharing restrictions in the academic community. However, in hypothesis development and in the interpretation of the results, attention was paid to reporting the associations and avoiding inference to causal relationships between different types of academia-industry knowledge transfer, individual and contextual factors, and different types of knowledge-sharing restrictions. Potential reverse causality was mitigated to a certain extent by also directly asking the survey respondents about the causes of different restrictions in their knowledge-sharing behaviors. The obtained results complement the analysis based on correlations between dependent and independent variables. Other studies in the field have pointed to similar problems (Gaughan and Corley, 2010). Some studies have succeeded in specifying temporal priority by using only the most recent experiences of survey respondents as a measure of knowledge-sharing restrictions. For example, Walsh et al. (2007) used regression analyses to test the reasons for researchers' non-compliance with requests for materials by assessing the factors (including the patent status of the requested material) conditioning whether a respondent's most recent request for materials was satisfied. In this research, a strategic decision was made to collect data from respondents for the period covering the past five years, rather than focusing only on the most recent period. This approach provided insights into the general patterns of academic researchers' sharing behaviors.

Future empirical research should consider temporal priority in the assessment of the impact of academia-industry knowledge transfer and individual and contextual factors on different types of knowledge-sharing restrictions in academia. Moreover, future studies could consider different types of knowledge when assessing the relationship between academia-industry knowledge transfer and knowledge-sharing restrictions. In particular, a distinction between the exchange of explicit (codified) and tacit knowledge could further contribute to the understanding of the determinants of knowledge-sharing restrictions in academic communities. Finally, cross-cultural studies are needed to assess how the cultural context impacts social norms. Accordingly, incentives or policy instruments geared toward sharing may need to be adapted to specific settings.

\section{References}

Abreu, M. and Grinevich, V. (2013), "The nature of academic entrepreneurship in the UK: widening the focus on entrepreneurial activities", Research Policy, Vol. 42 No. 2, pp. 408-422.

Agrawal, A. and Henderson, R. (2002), "Putting patents in context: exploring knowledge transfer from MIT", Management Science, Vol. 48 No. 1, pp. 44-60. 
Amayah, A.T. (2013), "Determinants of knowledge sharing in a public sector organization", Journal of Knowledge Management, Vol. 17 No. 3, pp. 454-471.

Anand, A., Walsh, I. and Moffett, S. (2019), "Does humility facilitate knowledge sharing? Investigating the role of humble knowledge inquiry and response", Journal of Knowledge Management, Vol. 23 No. 6 , pp. 1218-1244.

Andreoli-Versbach, P. and Mueller-Langer, F. (2014), "Open access to data: an ideal professed but not practised", Research Policy, Vol. 43 No. 9, pp. 1621-1633.

Armstrong, J.S. and Overton, T.S. (1977), "Estimating nonresponse bias in mail surveys", Journal of Marketing Research, Vol. 14 No. 3, pp. 396-402.

Aschhoff, B. and Grimpe, C. (2014), "Contemporaneous peer effects, career age and the industry involvement of academics in biotechnology”, Research Policy, Vol. 43 No. 2, pp. 367-381.

Azoulay, P., Ding, W. and Stuart, T. (2006), "The impact of academic patenting on the rate, quality and direction of (public) research", The Journal of Industrial Economics, Vol. 57 No. 4, pp. 637-676.

Baldini, N. (2008), "Negative effects of university patenting: myths and grounded evidence", Scientometrics, Vol. 75 No. 2, pp. 289-311.

Barros, M.V., Bigarelli Ferreira, M., Do Prado, G.F., Piekarski, C.M. and Picinin, C.T. (2020), "The interaction between knowledge management and technology transfer: a current literature review between 2013 and 2018", Journal of Technology Transfer.

Bikard, M., Vakili, K. and Teodoridis, F. (2018), "When collaboration bridges institutions: the impact of university-industry collaboration on academic productivity", Organization Science, Vol. 30 No. 2, pp. 426-445.

Blau, M. (1964), Exchange and Power in Social Life, Wiley, New York, NY.

Blumenthal, D., Campbell, E.C., Anderson, M.S., Causino, N. and Louis, K.S. (1997), "Withholding research results in academic life science. Evidence from a national survey of faculty", JAMA, Vol. 277 No. 15, pp. 1224-1228.

Blumenthal, D., Campbell, E.G., Causino, N. and Louis, K.S. (1996), "Participation of life-science faculty in research relationships with industry", New England Journal of Medicine, Vol. 335 No. 23, pp. 1734-1739.

Blumenthal, D., Campbell, E.G., Gokhale, M., Yucel, R., Clarridge, B., Hilgartner, S. and Holtzman, N.A. (2006), "Data withholding in genetics and the other life sciences: prevalences and predictors", Academic Medicine : Journal of the Association of American Medical Colleges, Vol. 81 No. 2, pp. 137-145.

Bock, G.W., Zmud, R.W., Kim, Y.G. and Lee, J.N. (2005), "Behavioral intention formation in knowledge sharing: examining the roles of extrinsic motivators, social-psychological forces, and organizational climate", MIS Quarterly, Vol. 29 No. 1, pp. 87-111.

Bourdieu, P. (1986), "The forms of Capital", Handbook of Theory and Research for the Sociology of Education, in Richardson, J.G. (Ed.), Greenwood. New York, NY, pp. 241-258.

Bouty, I. (2000), "Interpersonal and interaction influences on informal resource exchanges between R\&D researchers across organizational boundaries", Academy of Management Journal, Vol. 43 No. 1, pp. 50-65.

Breschi, S. and Catalini, C. (2010), "Tracing the links between science and technology: an exploratory analysis of scientists' and inventors' networks”, Research Policy, Vol. 39 No. 1, pp. 14-26.

Bruggemann, J., Crosetto, P., Meub, L. and Bizer, K. (2016), "Intellectual property rights hinder sequential innovation. Experimental evidence", Research Policy, Vol. 45 No. 10, pp. 2054-2068.

Campbell, E.G., Clarridge, B.R., Gokhale, M., Birenbaum, L., Hilgartner, S., Holtzman, N.A. and Blumenthal, D. (2002), "Data withholding in academic genetics: evidence from a national survey", JAMA, Vol. 287 No. 4, pp. 473-480.

Campbell, E.G., Powers, J.B., Blumenthal, D. and Biles, B. (2004), "Inside the triple helix: technology transfer and commercialization in the life sciences", Health Affairs, Vol. 23 No. 1, pp. 64-76.

Campbell, E.C., Weissman, J.S., Causino, N. and Blumenthal, D. (2000), "Data withholding in academic medicine: characteristics of faculty denied access to research results and biomaterials", Research Policy, Vol. 29 No. 2, pp. 303-312. 
Caulfield, T., Ogbogu, U., Murdoch, C. and Einsiedel, E. (2008), "Patents, commercialization and the Canadian stem cell research community", Regenerative Medicine, Vol. 3 No. 4, pp. 483-496.

Chiu, C.M., Hsu, M.H. and Wang, E.T.G. (2006), "Understanding knowledge sharing in virtual communities: an integration of social capital and social cognitive theories", Decision Support Systems, Vol. 42 No. 3, pp. 1872-1888.

Coleman, J.S. (1990), Foundations of Social Theory, Harvard University Press, Cambridge, MA.

Connelly, C.E., Zweig, D., Webster, J. and Trougakos, J.P. (2012), "Knowledge hiding in organizations", Journal of Organizational Behavior, Vol. 33 No. 1, pp. 64-88.

Czarnitzki, D., Grimpe, C. and Pellens, M. (2015), "Access to research inputs: open science versus the entrepreneurial university", The Journal of Technology Transfer, Vol. 40 No. 6, pp. 1050-1063.

D'Este, P. and Perkmann, M. (2011), "Why do academics engage with industry? The entrepreneurial university and individual motivations", The Journal of Technology Transfer, Vol. 36 No. 3, pp. 316-339.

Dasgupta, P. and David, P.A. (1994), "Toward a new economics of science", Research Policy, Vol. 23 No. 5, pp. 487-521.

Davis, L., Larsen, M.T. and Lotz, P. (2011), "Scientists' perspectives concerning the effects of university patenting on the conduct of academic research in the life sciences", The Journal of Technology Transfer, Vol. 36 No. 1, pp. 14-37.

Etzkowitz, H. and Leydesdorff, L. (2000), "The dynamics of innovation: from national systems and mode 2 to a triple helix of university-industry-government relations", Research Policy, Vol. 29 No. 2 , pp. 109-123.

European Commission (2020), "Open science factsheet", available at: https://ec.europa.eu/info/files/ open-science_en (accessed 21 January 2020).

Fabrizio, K.R. and Di Minin, A. (2008), "Commercializing the laboratory: faculty patenting and the open science environment", Research Policy, Vol. 37 No. 5, pp. 914-931.

Fornell, C. and Larcker, D.F. (1981), "Evaluating structural equation models with unobservable variables and measurement error", Journal of Marketing Research, Vol. 18 No. 1, pp. 39-50.

Fullwood, R. and Rowley, J. (2017), "An investigation of factors affecting knowledge sharing amongst UK academics", Journal of Knowledge Management, Vol. 21 No. 5, pp. 1254-1271.

Fullwood, R., Rowley, J. and Delbridge, R. (2013), "Knowledge sharing amongst academics in UK universities", Journal of Knowledge Management, Vol. 17 No. 1, pp. 123-136.

Gagné, M., Tian, A.W., Soo, C., Zhang, B., Ho, K.S.B. and Hosszu, K. (2019), "Different motivations for knowledge sharing and hiding: the role of motivating work design", Journal of Organizational Behavior, Vol. 40 No. 7, pp. 783-799

Gans, J.S. (2017), "Contracting over the disclosure of scientific knowledge: intellectual property and academic publication", Research Policy, Vol. 46 No. 4, pp. 820-835.

Gaughan, M. and Corley, E.A. (2010), "Science faculty at US research universities: the impacts of university research center-affiliation and gender on industrial activities", Technovation, Vol. 30 No. 3 , pp. 215-222.

Geuna, A. and Nesta, L.J.J. (2006), "University patenting and its effects on academic research: the emerging European evidence", Research Policy, Vol. 35 No. 6, pp. 790-807.

Gulbrandsen, M. and Smeby, J.-C. (2005), "Industry funding and university professors' research performance", Research Policy, Vol. 34 No. 6, pp. 932-950.

Haas, M.R. and Park, S. (2010), "To share or not to share? Professional norms, reference groups, and information withholding among life scientists", Organization Science, Vol. 21 No. 4, pp. 873-891.

Hackett, E.J. (1990), "Science as a vocation in the 1990s: the changing organizational culture of academic science", The Journal of Higher Education, Vol. 61 No. 3, pp. 241-279.

Haeussler, C. (2011), "Information-sharing in academia and the industry: a comparative study", Research Policy, Vol. 40 No. 1, pp. 105-122.

Haeussler, C. and Colyvas, J.A. (2011), "Breaking the ivory tower: academic entrepreneurship in the life sciences in UK and Germany", Research Policy, Vol. 40 No. 1, pp. 41-54. 
Haeussler, C., Jiang, L., Thursby, J. and Thursby, M. (2014), "Specific and general information sharing among competing academic researchers", Research Policy, Vol. 43 No. 3, pp. 465-475.

Hausman, J., Bronwyn, H.H. and Zvi, G. (1984), "Econometric models for count data with an application to the patents-R\&D relationship", Econometrica, Vol. 52 No., pp. 909-938.

Heller, M.A. and Eisenberg, R.S. (1998), "Can patents deter innovation? The anticommons in biomedical research", Science, Vol. 280 No. 5364, pp. 698-701.

Hernaus, T., Cerne, M., Connelly, C., Poloski Vokic, N. and Skerlavaj, M. (2019), "Evasive knowledge hiding in academia: when competitive individuals are asked to collaborate", Journal of Knowledge Management, Vol. 23 No. 4, pp. 597-618.

Ipe, M. (2003), "Knowledge sharing in organizations: a conceptual framework", Human Resource Development Review, Vol. 2 No. 4, pp. 337-359.

Kneller, R. (2001), "Technology transfer: a review for biomedical researchers", Clinical Cancer Research: An Official Journal of the American Association for Cancer Research, Vol. 7 No. 4, pp. 761-774.

Ku, M. (2019), "Similarity-dissimilarity and social capital in research knowledge networks: explaining knowledge sharing in academic institutions", Knowledge Management Research \& Practice, Vol. 17 No. 3, pp. 264-275.

Lee, S.J. (2018), "Academic entrepreneurship: exploring the effects of academic patenting activity on publication and collaboration among heterogeneous researchers in South Korea", Journal of Technology Transfer, doi: 10.1007/s10961-018-9711-3

Levin, D.Z. and Cross, R. (2004), "The strength of weak ties you can trust: the mediating role of trust in effective knowledge transfer", Management Science, Vol. 50 No. 11, pp. 1477-1490.

Merton, R.K. (1973), The Sociology of Science: Theoretical and Empirical Investigation, University of Chicago Press, Chicago, IL.

Murray, F. and Stern, S. (2007), "Do formal intellectual property rights hinder the free flow of scientific knowledge? An empirical test of the anti-commons hypothesis", Journal of Economic Behavior \& Organization, Vol. 63 No. 4, pp. 648-687.

Nahapiet, J. and Ghoshal, S. (1998), "Social capital, intellectual capital, and the organizational advantage", Academy of Management Review, Vol. 23 No. 2, pp. 242-266.

Nelson, A.J. (2016), "How to share a really good secret: managing sharing/secrecy tensions around scientific knowledge disclosure", Organization Science, Vol. 27 No. 2, pp. 265-285.

Pallant, J. (2001), SPSS Survival Manual, Open University Press, McGraw-Hill, Berkshire.

Perkmann, M., Tartari, V., Mckelvey, M., Autio, E., Brostrom, A., D’Este, P., Fini, R., Geuna, A., Grimaldi, R., Hughes, A., Krabel, S., Kitson, M., Llerena, P., Lissoni, F., Salter, A. and Sobrero, M. (2013), "Academic engagement and commercialisation: a review of the literature on university-industry relations", Research Policy, Vol. 42 No. 2, pp. 423-442.

Rodriguez, V., Janssens, F., Debackere, K. and Demoor, B. (2007), "Material transfer agreements and collaborative publication activity: the case of a biotechnology network", Research Evaluation, Vol. 16 No. 2, pp. 123-136.

Rosell, C. and Agrawal, A. (2009), "Have university knowledge flows narrowed? Evidence from patent data", Research Policy, Vol. 38 No. 1, pp. 1-13.

Salandra, R. (2018), "Knowledge dissemination in clinical trials: exploring influences of institutional support and type of innovation on selective reporting", Research Policy, Vol. 47 No. 7, pp. 1215-1228.

Schaeffer, V. (2019), "The use of material transfer agreements in academia: a threat to open science or a cooperation tool?", Research Policy, Vol. 48 No. 9.

Semerci, A.B. (2019), "Examination of knowledge hiding with conflict, competition and personal values", International Journal of Conflict Management, Vol. 30 No. 1, pp. 111-131.

Shibayama, S. (2012), "Conflict between entrepreneurship and open science, and the transition of scientific norms", The Journal of Technology Transfer, Vol. 37 No. 4, pp. 508-531.

Shibayama, S., Walsh, J.P. and Baba, Y. (2012), "Academic entrepreneurship and exchange of scientific resources: material transfer in life and materials sciences in Japanese universities", American Sociological Review, Vol. 77 No. 5, pp. 804-830. 
Stuart, T.E. and Ding, W., W. (2006), "When do scientists become entrepreneurs? The social structural antecedents of commercial activity in the academic life sciences", American Journal of Sociology, Vol. 112 No. 1, pp. 97-114

Tabachnick, B.G. and Fidell, L.S. (2019), Using Multivariate Statistics, 7th ed., Pearson, New York, NY.

Tan, C.N. (2016), "Enhancing knowledge sharing and research collaboration among academics: the role of knowledge management", Higher Education, Vol. 71 No. 4, pp. 525-556.

Thompson, N.C., Ziedonis, A.A. and Mowery, D.C. (2018), "University licensing and the flow of scientific knowledge", Research Policy, Vol. 47 No. 6, pp. 1060-1069.

Thursby, J.G., Haeussler, C., Thursby, M.C. and Jiang, L. (2018), "Prepublication disclosure of scientific results: norms, competition, and commercial orientation", Science Advances, Vol. 4 No. 5, p. 14.

Vogeli, C., Yucel, R., Bendavid, E., Jones, L.M., Anderson, M.S., Louis, K.S. and Campbell, E.G. (2006), "Data withholding and the next generation of scientists: results of a national survey", Academic Medicine: Journal of the Association of American Medical Colleges, Vol. 81 No. 2, pp. 128-136.

Walsh, J.P., Cohen, W.M. and Cho, C. (2007), "Where excludability matters: material versus intellectual property in academic biomedical research", Research Policy, Vol. 36 No. 8, pp. 1184-1203.

Walsh, J.P. and Huang, H. (2014), "Local context, academic entrepreneurship and open science: publication secrecy and commercial activity among Japanese and US scientists", Research Policy, Vol. 43 No. 2, pp. 245-260

Wang, S. and Noe, R.A. (2010), "Knowledge sharing: a review and directions for future research", Human Resource Management Review, Vol. 20 No. 2, pp. 115-131.

Wasko, M.M. and Faraj, S. (2005), "Why should I share? Examining social capital and knowledge contribution in electronic networks of practice", MIS Quarterly, Vol. 29 No. 1, pp. 35-57.

Zhang, X. and Jiang, J.Y. (2015), "With whom shall I share my knowledge? A recipient perspective of knowledge sharing", Journal of Knowledge Management, Vol. 19 No. 2, pp. 277-295.

Zhu, Y.Q. (2017), "Why and how knowledge sharing matters for R\&D engineers", R\&D Management, Vol. 47 No. 2, pp. 212-222. 
Appendix

Table A1 Correlations and AVE

\begin{tabular}{lcccccc} 
Construct & AVE & POEXP & COEXP & $\begin{array}{c}\text { Construct } \\
\text { TRUST }\end{array}$ & REPUT & ISCLIM \\
\hline POEXP & 0.67 & 0.82 & & & & \\
COEXP & 0.90 & 0.69 & 0.95 & & & \\
TRUST & 0.84 & 0.42 & 0.28 & 0.92 & & \\
REPUT & 0.74 & 0.19 & 0.18 & 0.16 & 0.86 & 0.83 \\
ISCLIM & 0.68 & 0.29 & 0.42 & 0.35 & 0.21 & 0.83
\end{tabular}

Notes: POEXP, personal outcome expectations; COEXP, community-related outcome expectations; TRUST, trust; REPUT, reputation; ISCLIM, institutional sharing climate. Diagonal figures (in italics) are calculated as the square root of the average variance extracted (AVE) and other figures represent the correlations among constructs. For discriminant validity, diagonal figures should exceed the other (non-diagonal) figures

\section{Corresponding author}

Mateja Drnovsek can be contacted at: mateja.drnovsek@ef.uni-lj.si

For instructions on how to order reprints of this article, please visit our website: www.emeraldgrouppublishing.com/licensing/reprints.htm

Or contact us for further details: permissions@emeraldinsight.com 